\title{
Probiotics: Immunomodulation and Evaluation of Safety and Efficacy
}

Janine Ezendam, $\mathrm{PhD}$, and Henk van Loveren, $\mathrm{PhD}$

The intake of probiotics has been associated with beneficial effects on the immune system, such as improved disease resistance and diminished risk of allergies. This review gives an overview of the immunomodulatory effects of probiotics investigated with in vitro assays, experimental animal models, and clinical trials, and explores possible mechanisms underlying the immunomodulatory effects. Immunomodulation, however, is not always beneficial and might induce detrimental effects; therefore, a scheme is proposed for benefit-risk assessment of immunomodulation by probiotics. Within this scheme, expert judgment based on data derived from a panel of in vitro assays, animal models, and clinical trials should lead to conclusions on efficacy and safety aspects of probiotics.

Key words: probiotics, immunomodulation, efficacy and safety evaluation

(C) 2006 International Life Sciences Institute

doi: 10.1301/nr.2006.jan.1-14

\section{INTRODUCTION}

Probiotics are dietary supplements that are by definition "living microorganisms, which, upon ingestion in sufficient numbers, exert health benefits." The most commonly used probiotics are lactic acid bacteria, mainly Lactobacillus and Bifidobacterium strains. Health effects that are ascribed to the intake of probiotics include beneficial effects on disease resistance, ${ }^{2-6}$ gastro-

Dr. Ezendam is with the National Institute of Public Health and the Environment, Laboratory for Toxicology, Pathology and Genetics, Bilthoven, The Netherlands; Dr. van Loveren is with the National Institute of Public Health and the Environment, Laboratory for Toxicology, Pathology and Genetics and the Department of Health Risk Analysis and Toxicology, Maastricht University, Maastricht, the Netherlands.

Please address all correspondence to: Dr. Janine Ezendam, RIVM, Department of Toxicology, Pathology and Genetics, P.O. Box 1, 3720 BA Bilthoven, The Netherlands; Phone: 31-30-2743447; Fax: 31-302744446; E-mail: Janine.Ezendam@rivm.nl. intestinal diseases, ${ }^{7-9}$ and allergies. ${ }^{10-12}$ Mechanisms underlying these beneficial effects are not completely understood, so the effects of probiotics should not be generalized, because different strains can exert different effects.

This review gives an overview of immunomodulation by probiotics in experimental animal models of allergy, autoimmunity, and inflammatory bowel disease (IBD), and presents available data on probiotic effects and the mechanisms involved as assessed in clinical trials. Modulation of the immune system might improve allergic, autoimmune, or inflammatory disorders, but may have undesired effects under certain circumstances.

There are currently no guidelines to evaluate the efficacy and safety of probiotics; therefore, an approach for efficacy and safety evaluation of probiotics will be proposed in this review. This approach is based on guidelines previously proposed by others, but is extended with respect to immunomodulatory effects and provides a decision scheme that can be used to evaluate newly marketed probiotic products. In this decision scheme, expert judgment is used to determine if health claims are plausible and adverse effects are possible.

\section{PROBIOTICS AND ALLERGIC DISEASES}

Several reports have shown that probiotic bacteria skew the Th1/Th2 balance toward Th1, which may beneficially down-regulate overactive Th2-mediated allergic responses. Stimulation of Th1 immunity has been confirmed in in vitro studies showing increased production of Th1 cytokines (IL-12, IL-18, and IFN- $\gamma$ ) in human monocytes and peripheral blood mononuclear cells (PBMCs) after incubation with several lactobacilli. ${ }^{13,14}$ Additionally, effects on the Th1/Th2 balance have been observed in animal models of allergy. In $\mathrm{BALB} / \mathrm{c}$ mice sensitized with ovalbumin and orally treated with Lactobacillus casei Shirota, splenocytes stimulated with ovalbumin ex vivo produced more Th1 cytokines (IFN- $\gamma$ ) and fewer Th2 cytokines (IL-4, IL-5, IL-6, and IL-10). Furthermore, the production of total and ovalbumin-specific IgE levels were suppressed. In a 
murine food allergy model, Lactobacillus plantarum increased plasma IL-12 levels and suppressed allergenspecific IgE levels, and this effect was IL-12 dependent. ${ }^{15}$ However, not all probiotic strains stimulated Th1 immunity. Lactobacillus rhamnosus HN001, for instance, stimulated a mixed Th1/Th2 cytokine pattern in a murine model of respiratory allergy. ${ }^{16}$ Thus, L. rhamnosus HN001 acted more as a general stimulator of the immune response, and therefore this probiotic might not be suitable for general use, but could possibly be used as an adjuvant.

Stimulation of Th1 immunity has been observed in clinical trials (Table 1). The effects of $L$. rhamnosus GG or a mixture containing $L$. rhamnosus $\mathrm{GG}, L$. rhamnosus LC7055, Bifidobacterium breve Bbi99, and Propionibacterium freudenreichii ssp. shermanii on infants with cow's milk allergy and IgE-associated dermatitis was investigated in a double-blind, placebo-controlled study. ${ }^{17}$ Intake of L. rhamnosus GG for 4 weeks alleviated skin symptoms, whereas the mixture did not affect clinical symptoms. This differential effect might be explained by differences in cytokine profiles measured after PBMC stimulation. IFN- $\gamma$ secretion was significantly increased after $L$. rhamnosus GG intervention. In contrast, the mixture of probiotics did not affect IFN- $\gamma$ secretion, but did increase the amount of IL-4. Apparently, the other probiotic strains present in the mixture stimulated a Th2 response that inhibited L. rhamnosus GG-induced Th1 responses. Furthermore, cytokine profiles appear to predict the effects on clinical symptoms. ${ }^{17}$

Several other studies report effects of probiotics on atopic eczema. In a randomized, double-blind, placebocontrolled study, 27 infants with atopic eczema received Bifidobacterium lactis Bb12, L. rhamnosus GG, or formula without probiotics for 2 months. Consumption of $B$. lactis $\mathrm{Bb} 12$ and L. rhamnosus GG decreased significantly the SCORAD (SCORing Atopic Dermatitis) score in all infants, reflecting an improvement in skin condition. In the control group, SCORAD decreased in 4 out of 9 infants. After 6 months, skin symptoms were absent in all groups. The intake of probiotics affected several immune parameters, such as decreased serum-soluble $\mathrm{CD}^{+}$, a marker for $\mathrm{T}$-cell activation, in both probiotic groups, whereas serum TGF- $\beta$ decreased in infants receiving $B$. lactis $\mathrm{Bb} 12$ and slightly but not significantly increased in the L. rhamnosus GG group. Also, eosinophilic protein $\mathrm{X}$, a urine marker for eosinophilic inflammatory activity, was reduced in both probiotic-supplemented groups. ${ }^{18}$

Beneficial effects of L. rhamnosus GG consumption on atopic eczema have been confirmed in another double-blind, randomized, placebo-controlled trial. L. rhamnosus GG $(\mathrm{n}=68)$ or placebo $(\mathrm{n}=64)$ was given prenatally to mothers with a family history of atopic disease. After delivery, breast-feeding mothers continued intake of $L$. rhamnosus GG and infants that were not breast-fed received L. rhamnosus GG for 6 months. Both treatments resulted in similar amounts of L. rhamnosus GG in infant feces. After 2 years, the percentage of infants diagnosed with atopic eczema was significantly reduced in the L. rhamnosus GG group (23\%) compared with the placebo group (46\%). However, surprisingly, probiotic intervention did not affect total $\mathrm{IgE}$ levels or the percentage of children with a positive skin-prick test, indicating that L. rhamnosus GG did not influence the allergic response. ${ }^{19}$ This cohort was re-examined at the age of 4 years. Although fewer children in the probiotic group were diagnosed with atopic eczema (14/53 compared with $25 / 54$ in the placebo group), there was also a non-significant trend toward increased rates of other atopic disorders (allergic rhinitis and asthma) in this group. $^{20}$

Another double-blind, placebo-controlled, crossover study investigated the effects of L. rhamnosus 19070-2 and Lactobacillus reuteri DSM 122460 on atopic eczema. Both probiotics were given in combination for 6 weeks to 1 - to 13 -year-old children $(n=43)$ with allergic and non-allergic eczema. After treatment, $56 \%$ of the children who received probiotics experienced improvement of eczema, whereas only $15 \%$ showed improved symptoms in the placebo group. The effects of probiotics seem to be more pronounced in allergic patients, because in allergic infants SCORAD decreased, whereas it was not affected in the total group. ${ }^{21}$

In the same cohort of patients, Rosenfeldt et al. ${ }^{22}$ found a positive association between impairment of intestinal permeability and severity of eczema. The intake of probiotics significantly decreased gastrointestinal symptoms and diminished intestinal permeability. Another study reported that infants with cow's milk allergy and atopic eczema suffered from intestinal inflammation, as demonstrated by increased fecal TNF- $\alpha$. After 1 month of intervention with L. rhamnosus GG $(\mathrm{n}=15)$, SCORAD scores had improved significantly and fecal TNF- $\alpha$ was reduced. Notably, in the placebo group the SCORAD and fecal TNF- $\alpha$ were reduced after 2 months. ${ }^{23}$ Thus, beneficial effects of probiotics might be explained by the stabilizing effects of probiotics on intestinal microflora and barrier function. In addition, the beneficial effects of probiotics might be explained by their influence on immunoregulatory mechanisms, because improvement of atopic dermatitis after consumption of L. rhamnosus GG for 4 weeks has been shown to be associated with elevated levels of serum IL-10, ${ }^{24}$ an anti-inflammatory cytokine that inhibits synthesis of several cytokines and down-regulates IgE synthesis. Thus, probiotics seem to improve atopic eczema via different mechanisms, which are listed in Table 2. 


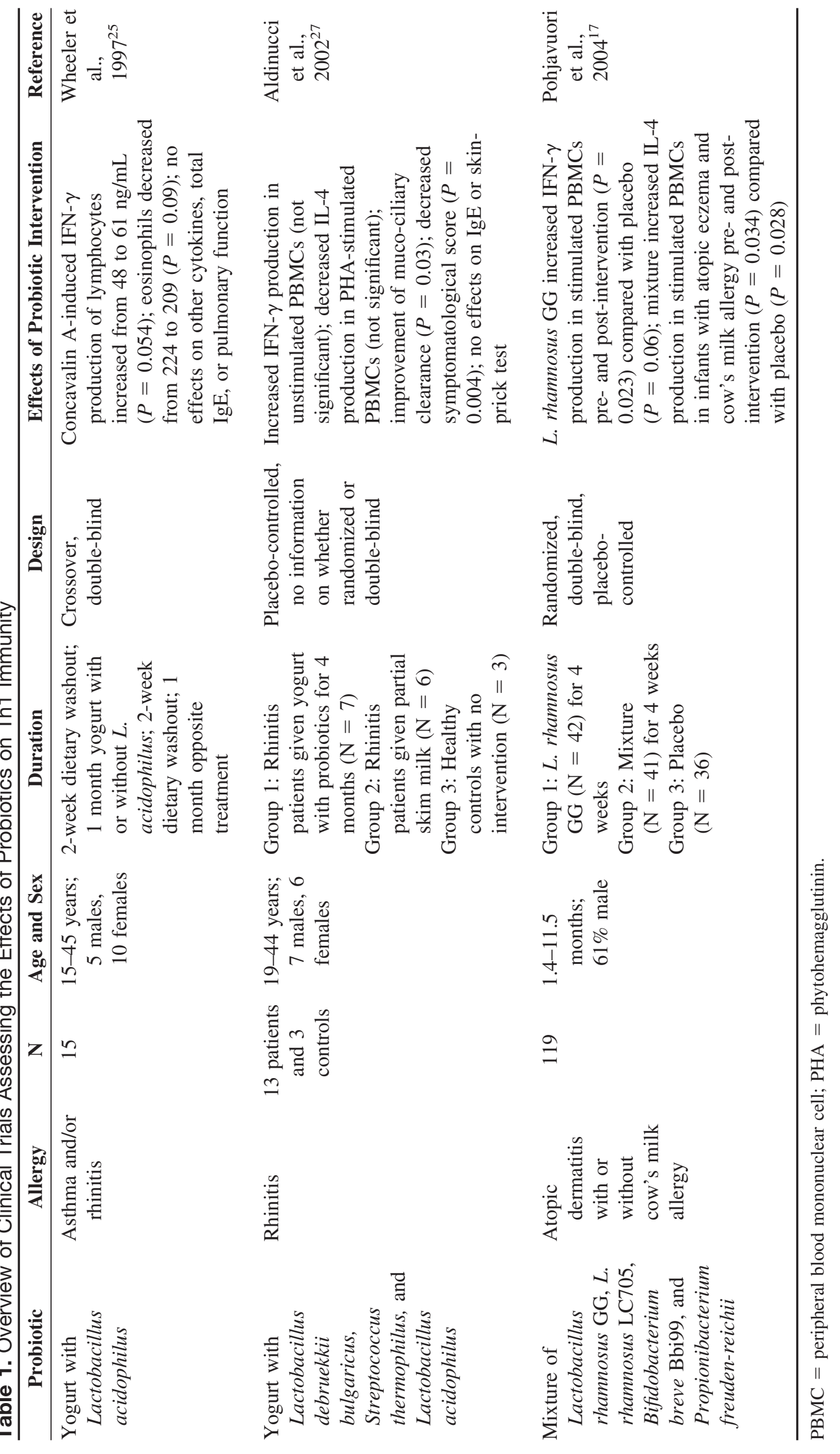




\begin{tabular}{|c|c|c|}
\hline Mechanism & Probiotic & Reference \\
\hline $\begin{array}{l}\text { Immune effects: decreased serum-soluble } \mathrm{CD}^{+}{ }^{+} \text {(a T-cell marker) } \\
\text { and increased TGF- } \beta \text { after Bifidobacterium lactis } \mathrm{Bbl} 2\end{array}$ & $\begin{array}{l}\text { B. lactis } \mathrm{Bb} 12 \text { or } \\
\text { Lactobacillus } \\
\text { rhamnosus } \mathrm{GG}\end{array}$ & Isolauri et al., $2000^{18}$ \\
\hline Effect on Th1 immunity (increased IFN- $\gamma$ ) & L. rhamnosus GG & Pohjavuori et al., $2004^{17}$ \\
\hline Immunoregulation (increased IL-10) & L. rhamnosus GG & Pessi et al., $2000^{24}$ \\
\hline Effects on intestinal permeability & L. rhamnosus GG & Rosenfeldt et al., $2004^{22}$ \\
\hline Alleviation of intestinal inflammation & L. rhamnosus $\mathrm{GG}$ & Majamaa et al., $1997^{23}$ \\
\hline
\end{tabular}

The hypothesized beneficial effects of probiotics on allergic disorders such as asthma or food allergy have not been convincingly demonstrated in clinical trials. In a crossover study, 20 patients with allergic rhinitis consumed either yogurt containing Lactobacillus bulgaricus and Streptococcus thermophilus or milk without probiotics for 1 month. After a washout period of 2 weeks, individuals who received yogurt with probiotics in the first period received milk for 1 month and vice versa. Several immune parameters were assessed: blood count and differentiation; serum $\operatorname{IgG}, \operatorname{IgA}, \operatorname{IgM}$, and $\operatorname{IgE}$; mitogen-induced proliferation and cytokine production; neutrophil chemotaxis and oxidative burst; phenotyping of blood cells with flow cytometry; and natural killer cell (NK) function. The consumption of yogurt slightly increased lymphocyte IL-2 production $(P=0.09)$, but other immune parameters were not affected. ${ }^{25} \mathrm{~A}$ similar crossover design was applied to study the effects of yogurt containing Lactobacillus acidophilus, L. bulgaricus, and S. thermophilus or the same yogurt without $L$. acidophilus in 15 atopic patients with asthma and/or rhinitis. There were no statistical differences observed pre- or post-treatment, but IFN- $\gamma$ production by PBMCs stimulated with concavalin A was slightly enhanced and blood eosinophilia were somewhat decreased. Serum IgE levels and clinical parameters such as pulmonary function and quality of life were not affected. ${ }^{26}$ Thus, although some immune parameters seem to be slightly modulated by the intake of probiotics, asthmatic symptoms do not improve.

In another study, ${ }^{27}$ patients with rhinitis received yogurt supplemented with Lactobacillus delbruekki, L. bulgaricus, S. thermophilus, L. acidophilus, and Bifidobacterium $(\mathrm{n}=7)$ or skim milk $(\mathrm{n}=6)$ for 4 months. After intervention with probiotics, cytokine levels were modulated, but this effect was not significant. IFN- $\gamma$ levels were increased in unstimulated PBMCs and IL-4 levels were decreased in phytohemagglutinin-stimulated PBMCs. Furthermore, there were no effects on skinprick tests and serum IgE. Remarkably, the subjective sensation of well-being was higher in patients who consumed yogurt with probiotics than in controls. ${ }^{27} \mathrm{In}$ addition, in patients with birch-pollen allergy $(n=18$ per group), the consumption of L. rhamnosus or placebo for
5.5 months starting 2 months before the pollen season did not alleviate symptoms or reduce the use of medication. $^{28}$

From the studies described above, it can be concluded that probiotics seem to accelerate improvement of atopic eczema, and L. rhamnosus $G G$ in particular appears to be effective. However, effects on other allergies are not very convincing, and the exact mechanisms are unclear. To obtain more insight into the complexity of probiotic effects on allergic diseases, mechanisms should be elucidated with experimental animal models and clinical trials should be performed with sufficient individuals per group to establish efficacy.

\section{SUPPLEMENTATION OF BABY FORMULAS WITH PROBIOTICS}

There are now baby formulas on the market that have been supplemented with probiotics (one, for example, contains B. lactis Bb12 and S. thermophilus Th4). The rationale for such a use is the observed association between microflora and allergies. Microflora of children from Estonia, a country with a low prevalence of allergies, contains higher numbers of lactobacilli compared with children from Sweden, a country with a high prevalence of allergies. ${ }^{29}$ In addition, allergic infants in both countries were less often colonized with lactobacilli and bifidobacteria than non-allergic children. ${ }^{30}$

A prospective study ${ }^{31}$ investigated the intestinal microflora of 76 infants with a predisposition to develop atopic diseases. At the age of 12 months, 29\% of these children had a positive skin-prick test. Remarkably, at the age of 3 weeks, these allergic infants had a lower ratio of bifidobacteria to clostridia compared with nonallergic infants. Dietary characteristics between atopic and non-atopic infants were similar. At the age of 3 weeks, $73 \%$ of the atopic and $68 \%$ of the non-atopic infants were exclusively breast-fed, $27 \%$ of the atopic and $28 \%$ of the non-atopic infants were breast-fed and formula-fed, and $4 \%$ of the non-atopic infants were formula-fed. At the age of 3 months, the dietary characteristics changed but were similar when comparing atopic (50\% breast-fed, $27 \%$ breast-fed and formula-fed, and $23 \%$ formula-fed) and non-atopic (54\% breast-fed, 
$26 \%$ breast-fed and formula-fed, and $20 \%$ formula-fed) subjects. The results of this study might indicate that differences in microflora early in life precede the development of atopy. ${ }^{31}$ It has also been shown that the microflora of formula-fed infants is more complex than that of breast-fed infants, and contains a complex mixture of anaerobic strains such as Bacteroides and Clostridium, while breast-fed infants are colonized with predominantly bifidobacteria and lactobacilli. ${ }^{19}$ Thus, supplementation of baby formulas with probiotics may modulate the microflora of infants and help to prevent allergies.

However, although probiotics have a long history of safe use, it is unknown if consumption early in life can induce adverse long-term effects. In a prospective, double-blind, randomized, placebo-controlled study, healthy infants age 3 to 24 months received a baby formula with B. lactis and S. thermophilus for a period of $210( \pm 127)$ days. Probiotics were well-tolerated by these infants without any influence on growth, formula intake, episodes of fever or diarrhea, or day care attendance. Furthermore, probiotics were associated with a significantly lower frequency of reported colic, irritability, and antibiotic use. ${ }^{32}$ The probiotic infant formulas currently on the market come with instructions that their use should be restricted to infants older than 4 months who are not immunocompromised. ${ }^{33}$

The effects of probiotic consumption immediately after birth, when the human gut is sterile and probiotics probably can colonize the host, are unknown. Experiments in congenitally immunodeficient, gnotobiotic, athymic mice have shown that $L$. acidophilus, $L$. reuteri, Bifidobacterium animalis, and L. rhamnosus $\mathrm{GG}$ are able to colonize and persist in the gastrointestinal tract. This was observed not only in adults, but also in offspring born from probiotic-exposed mothers. Infants were not given probiotics, but were exposed to them from feces and feed. More importantly, L. rhamnosus GG and $L$. reuteri caused some mortality in athymic neonates $(36 \%$ and $21 \%$, respectively), a phenomenon that did not occur in adults. ${ }^{34}$ Thus, probiotics might not be safe in immunodeficient neonates, and their prophylactic use to prevent allergies cannot be recommended, because both efficacy and safety issues are not convincingly demonstrated yet. As suggested previously, ${ }^{35}$ more information from well-designed clinical trials assessing the effects of probiotics on allergies is needed to make a proper decision on the pros and cons of probiotic use in infants.

\section{PROBIOTICS AND AUTOIMMUNITY}

Although most studies focus on the effects of probiotics on allergies, there have also been studies investigating their effects on autoimmunity. Stimula- tion of Th1 immunity by probiotics would not be desirable in autoimmunity, because enhanced Th1 responsiveness may aggravate Th1-mediated autoimmune diseases. Data obtained in experimental animal models suggest that probiotics can modulate the immune system via other mechanisms. The effects of $L$. casei Shirota have been studied in two experimental models of insulin-dependent diabetes mellitus: alloxan-induced diabetes and non-obese diabetic (NOD) mice. ${ }^{36,37}$ In both models, L. casei Shirota decreased the incidence of diabetes, slightly reduced plasma glucose levels, and prevented the destruction of the $\beta$-cells and islets of Langerhans. In the alloxan model, destruction of $\beta$-cells was caused by nitric oxide. After probiotic administration, plasma nitric oxide levels were reduced via an unexplained mechanism. ${ }^{36}$ The effects of $L$. casei Shirota in NOD mice might be explained by the observed shift in Th1/Th2 balance to Th2. Spleen cells stimulated with concavalin A produced less IFN- $\gamma$ and more IL-2, IL-4, IL-6, and IL-10. Furthermore, after L. casei Shirota treatment, the number of $\mathrm{CD} 8^{+} \mathrm{T}$-cells, which are involved in the destruction of $\beta$-cells, was lower. ${ }^{37}$

L. casei Shirota seemed to stimulate Th1 responses in this experimental diabetes model, ${ }^{37}$ while in an experimental allergy model, L. casei Shirota decreased Th1 responses. ${ }^{38}$ This suggests that the immunomodulatory effects of probiotics cannot simply be explained by skewing of the Th1/Th2 balance to Th1. Supposedly, immunomodulation is regulated at another level. In vitro experiments have shown that Lactobacillus paracasei NCC2461 inhibited T-cell proliferation via induction of a regulatory cytokine profile with enhanced levels of IL-10 and TGF- $\beta$ and decreased levels of both Th1 and Th2 cytokines. ${ }^{39}$ L. casei Shirota may have affected both autoimmunity and allergy via immunoregulatory mechanisms.

Immunoregulation induced by probiotics could be involved in experimental murine models of rheumatoid arthritis. ${ }^{40,41}$ Lactobacillus salivarius 118 reduced disease severity in collagen-induced arthritis. Furthermore, this probiotic strain reduced IL-12 and TNF- $\alpha$ and increased TGF- $\beta$ in mice with experimental colitis. ${ }^{40}$ Improvement of arthritis might be caused by down-regulation of IL-12 and TNF- $\alpha$, cytokines that play a critical role in collagen-induced arthritis. ${ }^{42}$ L. casei Shirota reduced anticollagen-specific immunoglobulin levels and specific delayed-type hypersensitivity (DTH) responses. Furthermore, L. casei Shirota reduced Th1 responses but not Th2 responses, again illustrating that that probiotics do not always stimulate Th1 responses. ${ }^{41}$ In tropomyosin arthritis or adjuvant arthritis in rats, intervention with $L$. rhamnosus GG reduced inflammation but did not affect anti-tropomyosin antibody titers. ${ }^{43}$ 
It has been suggested that there is an association between intestinal microflora and rheumatoid arthritis. Microflora from patients with newly developed rheumatoid arthritis have a significantly different bacterial flora in their feces compared with controls. ${ }^{44}$ This may suggest that probiotics affect experimental arthritis by influencing intestinal microflora; however, this has not been seen in experimental models of arthritis. Information on the effects of probiotics in patients with rheumatoid arthritis is also scarce, due to a lack of clinical trials investigating the effects of probiotics. In one placebocontrolled trial, patients were randomized to receive $L$. rhamnosus $\mathrm{GG}(\mathrm{n}=8)$ or placebo $(\mathrm{n}=13)$ for 12 months. Intervention with L. rhamnosus GG did not improve clinical symptoms or anti- and pro-inflammatory cytokines in serum. However, probiotic intake seemed to reduce the occurrence of swollen joints, although this effect was not significant. ${ }^{45}$

Clearly, more clinical trials are needed to confirm the effects of probiotics on immunity that have been observed in experimental arthritis models. Experimental data obtained in a murine model for multiple sclerosis (experimental autoimmune encephalomyelitis) demonstrated that different probiotic strains induced opposing effects. The probiotic $L$. reuteri aggravated the disease, whereas L. casei and Lactobacillus murines ameliorated it. Cytokine profiles induced by the different strains seem to predict clinical outcome. $L$. reuteri induced a Th1-like profile (TNF- $\alpha$ and IL-2) in the gut and adjuvated the immune response to a parenterally administered antigen. In contrast, $L$. casei induced immunoregulatory cytokines (TGF- $\beta$ and IL-10) in the gut and did not show any adjuvant activity. ${ }^{46}$ These findings suggest that probiotics with intrinsic adjuvant activity can have detrimental effects on autoimmune diseases, and that cytokine profiles might be useful for proper strain selection.

\section{EFFECTS OF PROBIOTICS ON INFLAMMATORY BOWEL DISEASE}

More mechanistic information has been obtained in experiments studying the effects of probiotics on IBD (Crohn's disease and ulcerative colitis). In IBD, tolerance of the mucosal immune system against the intestinal microflora appears to be lost, and this is thought to contribute to intestinal inflammation. ${ }^{47}$ Probiotics have been shown to be beneficial in several animal models of IBD. For example, the administration of $L$. reuteri in a rat model of acetic acid-induced colitis improved gut permeability and reduced intestinal inflammation. ${ }^{48}$ Also, L. plantarum DSM 9843, Bifidobacterium sp. 3B1, and Bifidobacterium infantis DSM 15158 were all able to significantly improve the clinical score in dextran sulfate sodium-induced colitis. ${ }^{49}$ In contrast, L. plantarum could not reduce the severity of colitis nor improve gut permeability in trinitrobenzene sulfonic acid-induced colitis. ${ }^{50}$

In humans, effects of the probiotic Escherichia coli Nissle 1917 on ulcerative colitis have been studied in a randomized, double-blind trial. Patients were randomized to treatment with either a probiotic $(n=110)$ or mesalazine $(\mathrm{n}=112)$, the drug that is normally prescribed to treat colitis, for 12 months. Relapses were similar in patients treated with E. coli Nissle 1917 (37\%) and mesalazine (34\%), and E. coli Nissle 1917 appeared to be equivalent to mesalazine in maintaining remission. ${ }^{51}$ In a comparable study design, 57 active colitis patients were treated with E. coli Nissle 1917 and 59 with mesalazine for 12 months. A total of 44 mesazalinetreated patients and 39 patients receiving $E$. coli Nissle 1917 went into remission and could be followed for relapse. Again, E. coli Nissle 1917 was as effective as mesalazine in maintaining remission. ${ }^{52}$

In a randomized, placebo-controlled trial, effects of the probiotic cocktail VSL\#3, containing L. casei, L. plantarum, L. acidophilus, Lactobacillus delbrueckii bulgaricus, B. breve, B. longum, B. infantis, and Streptococcus salivarius thermophilus, on remissive pouchitis were investigated. Patients received either VSL\#3 ( $\mathrm{n}=$ $20)$ or placebo $(\mathrm{n}=16)$ for 12 months, and remission was maintained in $85 \%$ of the patients who received the VSL\#3 cocktail and in $6 \%$ of those who received the placebo. Thus, the VSL\#3 cocktail effectively maintained remission. ${ }^{53}$

In another randomized, placebo-controlled trial, the effects of L. rhamnosus GG on Crohn's disease were investigated. Only those patients who had had all of the inflamed gut removed surgically were included. Patients were randomized to receive either $L$. rhamnosus GG $(n=23)$ or placebo $(n=22)$. However, the intake of probiotics did not prevent endoscopic recurrence of the disease. ${ }^{54}$ Thus, not all probiotic strains seem to be equally effective in treating IBD. Furthermore, Crohn's disease and colitis do not have the same etiology, and this might explain the different effects. Table 3 summarizes the effects of probiotics on IBD.

\section{INVOLVEMENT OF TOLL-LIKE RECEPTORS AND IMMUNOREGULATION}

Exact mechanisms underlying the beneficial effects of probiotics are not completely understood, but might involve pattern recognition molecules such as toll-like receptors (TLRs), which recognize pathogens by their evolutionarily conserved microbial components. ${ }^{55}$ TLRs are essential in innate defense against pathogens, and trigger adaptive immune responses. ${ }^{56}$ Several studies suggest that TLRs might be involved in the beneficial effects elicited by probiotics. For example, E. coli Nissle 


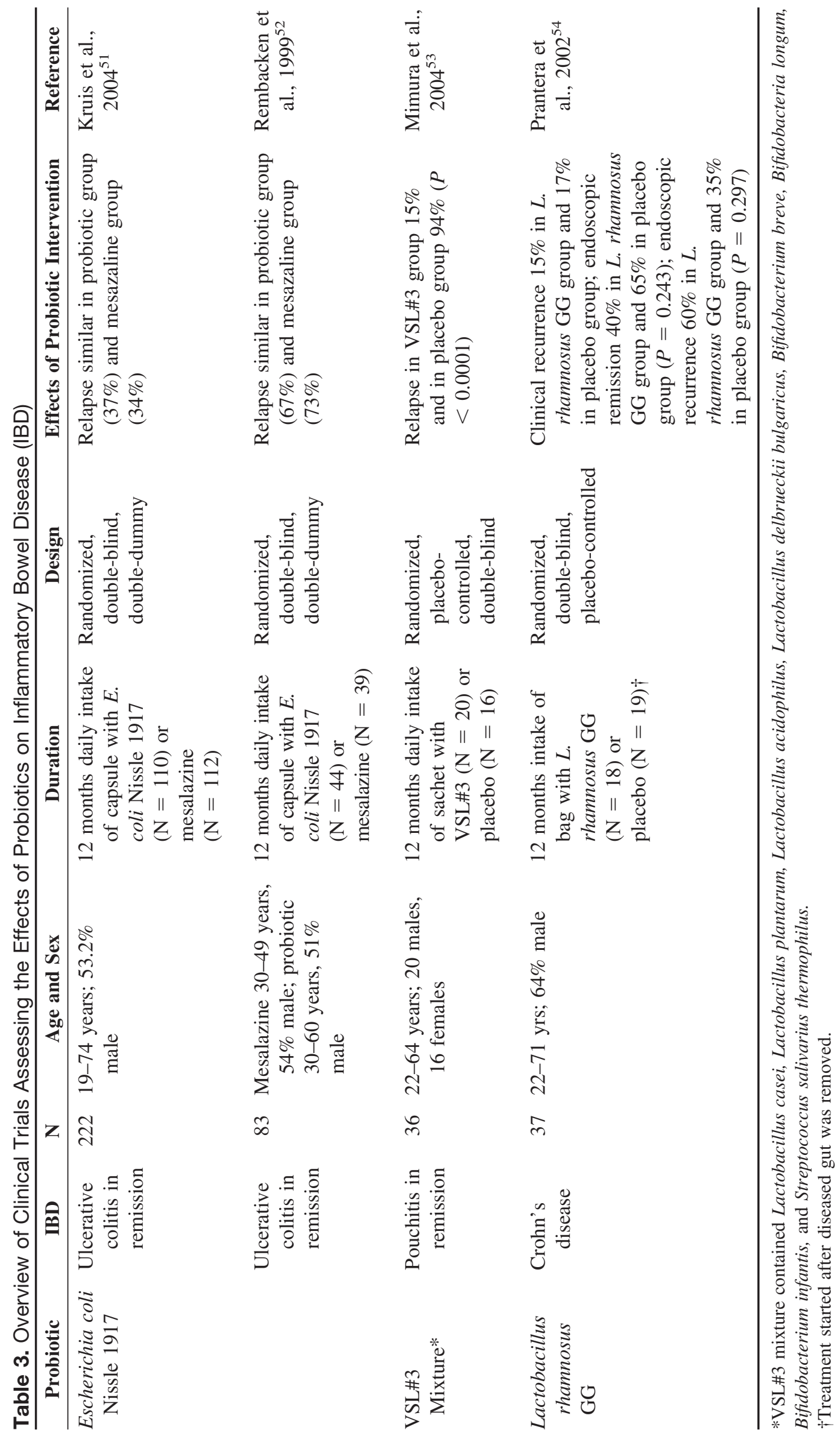


1917 significantly reduced the capacity of peripheral blood T-cells to proliferate following antigen stimulation; inhibited the production of IL-2, TNF- $\alpha$, and IFN- $\gamma$; and enhanced IL-10 production. The effects of $E$. coli Nissle 1917 seem to be mediated by TLR2, because no suppression was observed in T-cells from TLR2deficient mice. ${ }^{57}$ Aberrant T-cell responses seem to play an important role in the loss of tolerance against intestinal microflora, and the suppressive effects of probiotics on T-cells mediated via TLR signaling might therefore reduce intestinal inflammation. The involvement of TLRs in the improvement of colitis was observed in dextran sulfate sodium-induced colitis. The probiotic cocktail VSL\#3 improved colitis in wild-type mice but not in TLR9-deficient mice. ${ }^{58}$

Regulatory cytokines also seem to be involved in the beneficial effects of probiotics on colitis. The VSL\#3 cocktail administered for 3 weeks to mice after recovery from initial induction of trinitrobenzene sulfonic acidinduced colitis and before second induction of (recurrent) trinitrobenzene sulfonic acid-induced colitis resulted in a milder form of colitis, which was attributed to elevated IL-10 production and increased regulatory CD4 ${ }^{+}$T-cells. ${ }^{59}$

It is unknown what triggers the activation of regulatory T-cells after probiotic administration, but dendritic cells might be involved. Dendritic cells are abundantly present in the gastrointestinal tract and are the principal stimulators of naive T-cells. As such, they play a crucial role in the polarization of the immune response to Th1, Th2, and regulatory T-cell responses. ${ }^{60}$ In vitro studies have shown that probiotics affect dendritic cell maturation and cytokine secretion, although different and opposing effects were observed (e.g., production of Th1 cytokines, immunoregulatory cytokines, or both). These differences might be explained by differences in Lactobacillus strains, in the source of dendritic cells (human or murine), or in culture conditions and exposure time. For example, incubation of mouse bone marrow-derived dendritic cells with probiotic strains showed that all strains induced IL-12, IL-6, TNF- $\alpha$, and IL-10 production, but not all strains were equally effective. In addition, all strains up-regulated maturation surface markers on dendritic cells (e.g., MHCII and CD86), but strains that strongly induced IL-12 were the most effective. ${ }^{61}$ Maturation of human peripheral blood-derived dendritic cells was observed after incubation with Lactobacillus gasseri, Lactobacillus johnsonii, and L. reuteri, but these strains only induced secretion of IL-12, not IL-10, and skewed T-cell polarization toward Th1 and Tc1 cells. Interestingly, all probiotic strains up-regulated TLR2 transcripts in dendritic cells, suggesting that TLR signaling could be involved in dendritic cell maturation and activation. $^{62}$
The probiotic cocktail VSL\#3 induced IL-10 production in human intestinal lamina propria or bloodderived dendritic cells and inhibited the generation of Th1 cells. Interestingly, individual strains from the VSL\#3 cocktail displayed opposing effects. All strains down-regulated IL-12 production, the bifidobacteria stimulated IL-10, and all of the lactobacilli except $L$. acidophilus down-regulated IL-10. ${ }^{63}$ Similarly, incubation of human monocyte-derived dendritic cells with $L$. rhamnosus induced dendritic cell maturation to a more regulatory profile, as judged by effects on T-cells. Priming T-cells with L. rhamnosus-matured dendritic cells induced hyporesponsive T-cells that produced less IL-2, IL-4, and IL-10 than T-cells primed with lipopolysaccharide-matured dendritic cells. To confirm these in vitro data, six patients with Crohn's disease and six healthy subjects received L. rhamnosus for 2 weeks. Ex vivo stimulation of peripheral T-cells showed a similar hyporesponsiveness after probiotic intervention, including decreased Th1 and Th2 responses without up-regulation of immunoregulatory cytokines, in both healthy volunteers and patients with Crohn's disease. ${ }^{64}$

Probiotics seem to modulate the immune system via several mechanisms, including TLR signaling and dendritic cell maturation, which can lead to stimulation of Th1 responses, activation of regulatory T-cells, or induction of hyporesponsiveness. Therefore, probiotics and probiotic effects cannot be generalized, and all strains may not be suitable for common use. For example, the induction of immunoregulation can be beneficial in both allergic and autoimmune diseases, whereas probiotics that have adjuvant properties or stimulate the Th1 response might exacerbate autoimmune diseases. Furthermore, the induction of hyporesponsive T-cells might impair immunity against infections, and is therefore not suitable for use in the general population. For example, L. rhamnosus GG induced different effects in healthy volunteers and milk-hypersensitive subjects. In the latter, L. rhamnosus GG intake prevented the increased expression of phagocytosis receptors, while in controls it appeared to have an immunostimulatory effect, since receptor expression was increased. This suggests that susceptibility for immunomodulation by probiotics is different in healthy and hypersensitive subjects. ${ }^{65}$ Guidelines on how to evaluate probiotic strains clearly need to be set.

\section{ASSESSMENT OF EFFICACY AND SAFETY OF PROBIOTICS}

In the European Union, probiotics are regulated via the Novel Food Regulation (258/97/EC). In short, this regulation is only applied to strains that were not used 
before 1997 and concerns novel foods or food ingredients. The definition of novel foods is "foods and food ingredients which have not hitherto been used for human consumption to a significant degree within the community." To date, only in Denmark is it required that the relevant authority be notified by the manufacturer prior to the use of new probiotic strains. In France, a premarket approval system for novel strains is being considered, and proposed recommendations were published by Agence Française de Sécurité Sanitaire des Aliments.

In the United States, a probiotic used in food can be classified as an additive, in which case it has to be approved by the Food and Drug Administration (FDA) on the basis of safety and efficacy data, or it can be considered "generally recognized as safe" (GRAS). The GRAS status is given to a probiotic when it has a history of safe use in food dating before 1958 or has been identified as safe by expert judgment under the conditions of intended use. ${ }^{66,67}$

The approach proposed by the Food and Agriculture
Organization of the United Nations (FAO) and the World Health Organization (WHO) may be useful in evaluating newly discovered probiotics. ${ }^{68}$ According to this scheme (Figure 1), the phenotype and genotype of probiotic strains should first be established. Thereafter, assessment of safety and efficacy and functional characterization of probiotics should be performed with in vitro assays and animal studies. In vitro assays can be used to gain knowledge of probiotic strains and mechanisms of their effects (e.g., adherence to epithelial cell lines or ability to reduce pathogen adhesion to surfaces). If possible, in vitro effects should be confirmed in animal models. Then, probiotics have to be tested using standard methods in two clinical evaluations: phase 1 (safety assessment) and phase 2 (efficacy assessment) studies. If these clinical studies confirm efficacy and safety of a probiotic strain, then that strain can be marketed as a probiotic food. When a claim is made that a probiotic can alter a disease state, then a phase 3 study must be performed. This claim can only be made when it is based on sound

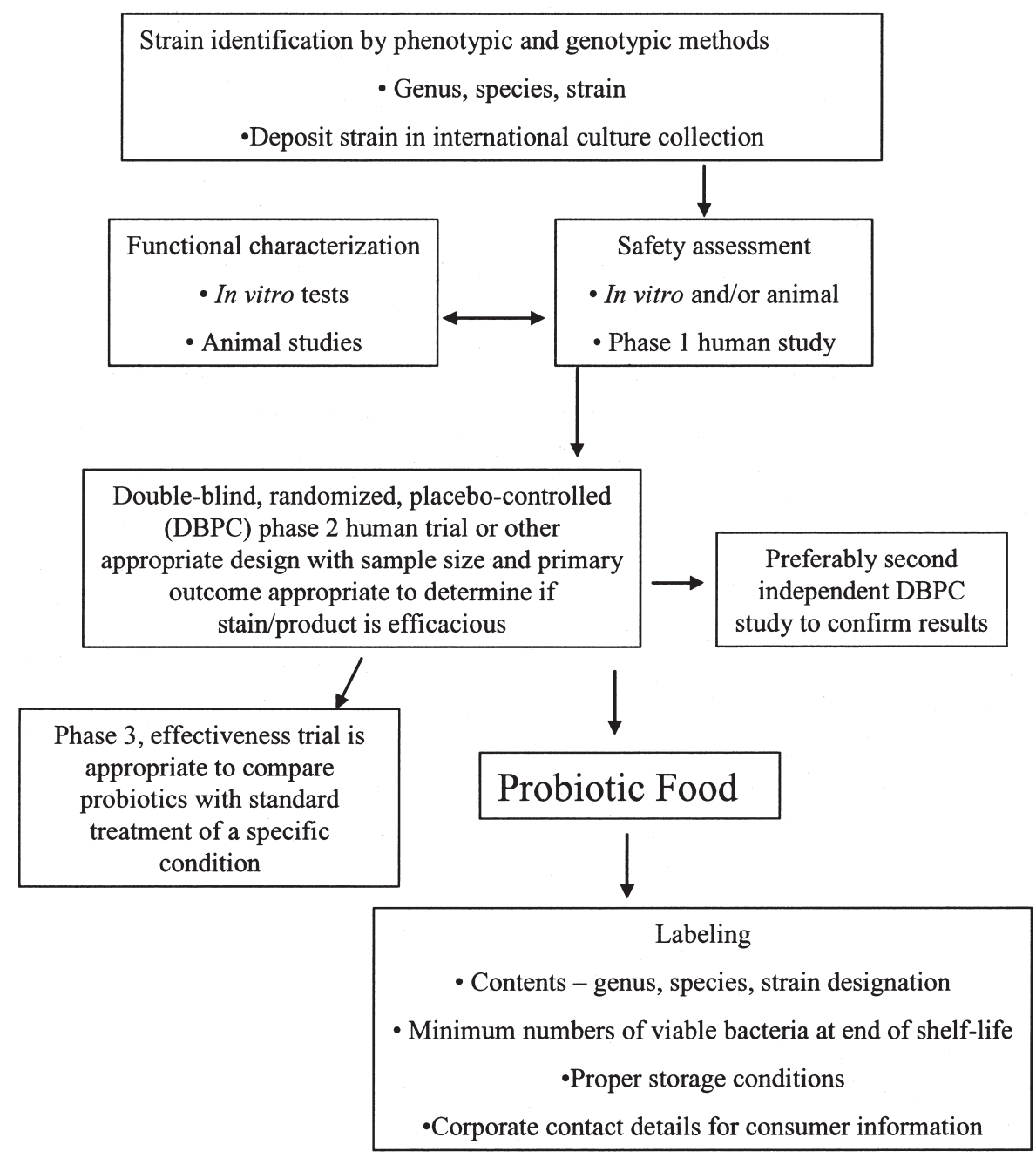

Figure 1. Food and Agriculture Organization of the United Nations (FAO) and World Health Organization (WHO) guidelines for the evaluation of probiotics for food use. Available at: ftp://ftp.fao.org/es/esn/food/wgreport2.pdf. 
scientific evidence. Finally, the scheme provides recommendations for labeling of probiotic foods. ${ }^{68}$

A similar approach has been proposed by Salminen et al. ${ }^{69}$ (Figure 2), who recommends that the safety of probiotics should be assessed in three steps. In the first, the intrinsic properties of the strain (e.g., enzymatic properties) should be studied. In the second, safety and stability should be evaluated (e.g., survival in the gastrointestinal tract is a prerequisite for a probiotic strain, but strains that can translocate and invade the host might cause unwanted side effects). In the third step, interactions between strain and host are studied. In this last step, several functional and physiological aspects of probiotic strains should be studied, either with in vitro assays or animal models. For example, adherence to intestinal epithelium can be studied with epithelial cell lines and translocation can be studied in animal models. Ultimately, clinical side effects should be studied in healthy volunteers and patients.

In this approach, the stimulation and suppression of immune responses is mentioned. Clearly, immunomodulation should be investigated further, because several studies have shown the immunomodulatory effects of probiotics, and immunomodulation might induce unwanted effects on the host. Accordingly, in the efficacy and safety assessment of probiotics, evaluation of the immunomodulatory properties of a probiotic strain should be included. Immunomodulatory effects of probiotics vary with different types of bacteria and in different experimental models, so immunomodulation cannot be assessed with one single assay, but requires a panel of assays.

We propose a decision scheme based on another scheme presented by Salminen et al. ${ }^{70}$ (Figure 3). To assess immunomodulation, the effects of probiotics should be studied with in vitro assays, experimental animal models, and clinical trials. Initially, in vitro assays should be used to determine cytokine profiles. Effects of probiotics should be studied in monocytes, macrophages, or PBMCs, because it has been shown that probiotics can induce the production of pro-inflammatory cytokines in macrophages ${ }^{70}$ and Th1 cytokines in peripheral blood monocytes. ${ }^{14}$ In addition, effects on dendritic cell maturation and activation should be in-

\section{General Aspects \\ General Aspects}

.

Safety and stability

Safety and stability

Functional and physiological aspects
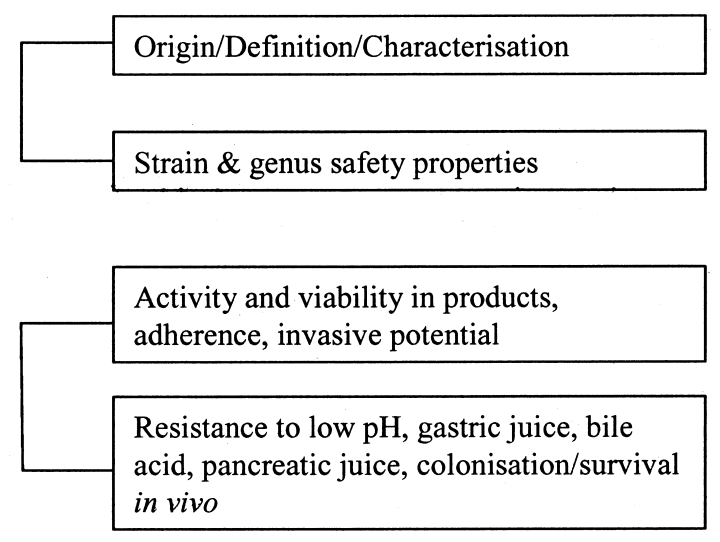

\begin{tabular}{|c|}
\hline $\begin{array}{l}\text { Adherence to intestinal epithelium/tissue/ } \\
\text { virulence }\end{array}$ \\
\hline and/or \\
\hline Adherence to pathogens \\
\hline Antimicrobial activity \\
\hline and/or \\
\hline $\begin{array}{l}\text { Stimulation/suppression of immune } \\
\text { response }\end{array}$ \\
\hline and/or \\
\hline $\begin{array}{l}\text { Selective stimulation of beneficial bacteria } \\
\text { and suppression of harmful bacteria }\end{array}$ \\
\hline and/or \\
\hline Clinical side effects volunteers/patients \\
\hline
\end{tabular}

Figure 2. Decision scheme for safety evaluation of probiotics (from Salminen et al., 199869). 


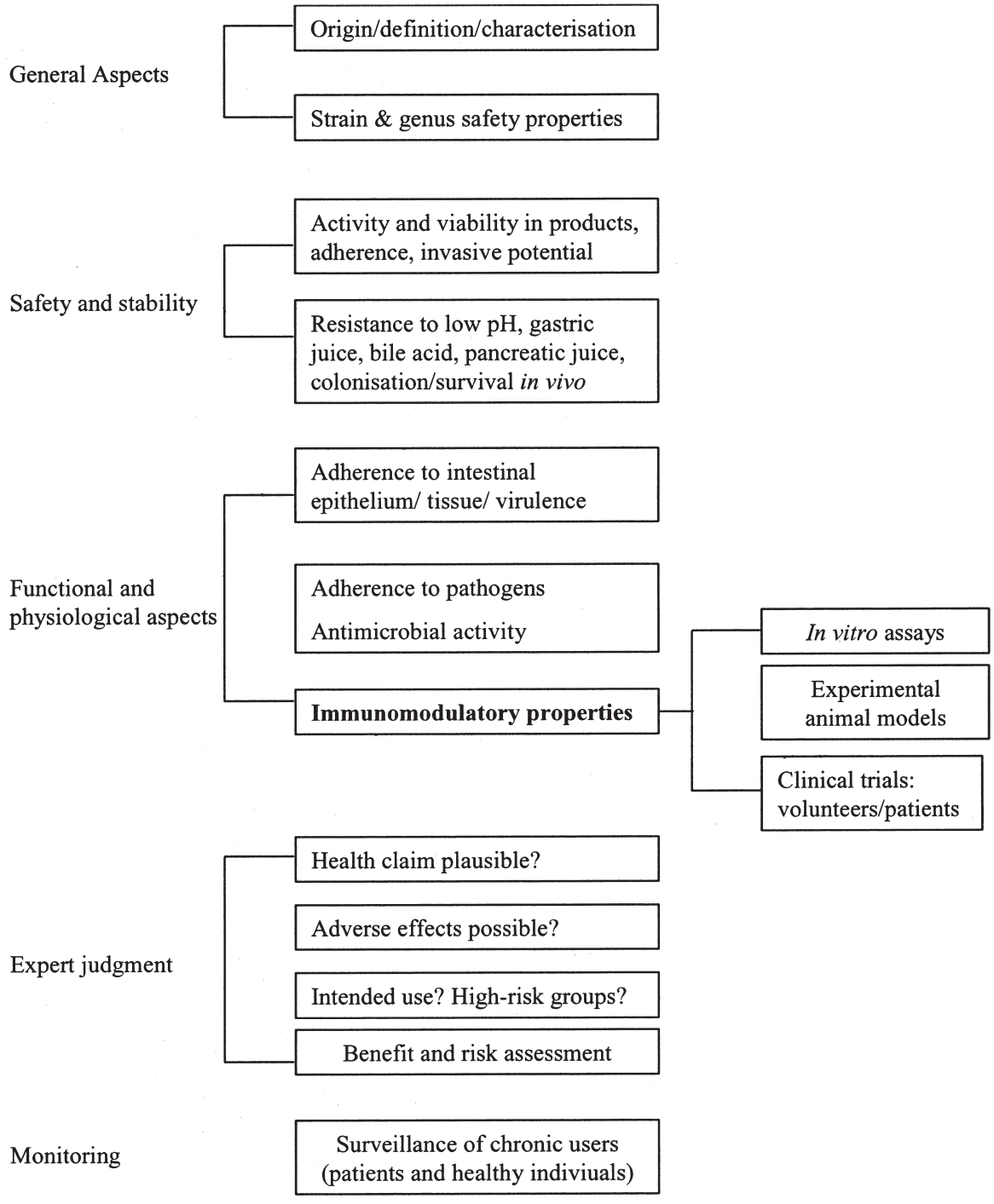

Figure 3. Proposal for a scheme that can be used for efficacy and safety evaluation of probiotics (adapted from Salminen et al., $1998^{70}$ ).

cluded, because probiotics can affect this maturation differently, ${ }^{61,63}$ and this can influence the type of immune response generated. ${ }^{60}$

Cytokine profiles may be predictive for the outcome of immunomodulatory effects of a probiotic strain, but additional information should be obtained from experimental animal studies. Effects of probiotics should be tested in several experimental disease models to establish efficacy and possible unwanted effects. Preferably, probiotics should be tested in host resistance models (cellular immunity), allergy models (Th2-mediated immune responses), autoimmunity models, and contact hypersensitivity models (the latter two are both Th1-mediated immune responses). Ultimately, the probiotic strain should be tested in clinical trials with the approach that was proposed by the FAO/WHO (Figure 1) using standard phase 1 and 2 (and phase 3 if necessary) studies. ${ }^{68}$ Finally, all data available on a probiotic strain or probiotic product should be evaluated by an expert. Important issues at this point are the plausibility of the health claim and the possibility of adverse effects. Intended use should also be taken into account.

The proposed approach is similar to the GRAS notification procedure used in the United States in that it is usually restricted to a specific application and not to general use. For example, the FDA has accepted the use of B. lactis Bb12 and S. thermophilus Th3 as ingredients for an infant formula under the condition that it is intended for consumption by infants 4 months and older who are not immunocompromised. ${ }^{33}$ In the same manner, the acceptance of probiotic products could only be approved under certain restrictions such age and immune status.

In the European Union, there is no special regulation for supplementation of infant formulas with probiotics. The Scientific Committee on Food of the European Commission has recommended that infant formulas supplemented with probiotics should only be marketed if 
their benefit and safety have been evaluated according to principles outlined by them. ${ }^{71}$ In addition, the European Society for Paediatric Gastroenterology, Hepatology and Nutrition Committee on Nutrition concluded that further evaluation of the safety and efficacy of probiotic supplementation of dietetic products for infants is necessary. Concerns have been raised that available scientific data are not sufficient to support the use of probiotics in healthy newborn and very young infants with immature defense systems. ${ }^{72}$ Finally, according to the scheme presented in Figure 3, the surveillance of probiotic products on the market could provide more insight into both efficacy and side effects after long-term consumption.

\section{CONCLUDING REMARKS}

Although the immunomodulatory effects of probiotics have been demonstrated in experimental animal models of allergy, autoimmunity, and IBD, information from clinical trials in humans is scarce. Furthermore, some studies suggest that probiotics could induce detrimental effects. Therefore, more research, especially in the form of well-designed clinical trials, is needed to evaluate the efficacy and safety of probiotics. The evaluation scheme proposed here could provide a tool to standardize this evaluation to obtain more insight into the complex nature of the effects of probiotics.

\section{REFERENCES}

1. Schrezenmeir J, Vrese M. Probiotics, prebiotics, and synbiotics-approaching a definition. Am J Clin Nutr. 2001;73(suppl 2):361S-364S.

2. De Waard R, Claassen E, Bokken GC, Buiting B, Garssen J, Vos JG. Enhanced immunological memory responses to Listeria monocytogenes in rodents, as measured by delayed-type hypersensitivity (DTH), adoptive transfer of DTH, and protective immunity, following Lactobacillus casei Shirota ingestion. Clin Diagn Lab Immunol. 2003;10:59-65.

3. De Waard R, Garssen J, Snel J, et al. Enhanced antigen-specific delayed-type hypersensitivity and immunoglobulin G2b responses after oral administration of viable Lactobacillus casei YIT9029 in Wistar and Brown Norway rats. Clin Diagn Lab Immunol. 2001;8:762-767.

4. Alvarez S, Herrero C, Bru E, Perdigon G. Effect of Lactobacillus casei and yogurt administration on prevention of Pseudomonas aeruginosa infection in young mice. J Food Prot. 2001;64:1768-1774.

5. Hatakka K, Savilahti E, Ponka A, et al. Effect of long term consumption of probiotic milk on infections in children attending day care centres: double blind, randomised trial. BMJ. 2001;322:1327.

6. Weizman Z, Asli G, Alsheikh A. Effect of a probiotic infant formula on infections in child care centers: comparison of two probiotic agents. Pediatrics. 2005;115:5-9.

7. Madsen KL. The use of probiotics in gastrointestinal disease. Can J Gastroenterol. 2001;15:817-822.
8. Shanahan F. Probiotics and inflammatory bowel disease: from fads and fantasy to facts and future. Br J Nutr. 2002;88(suppl 1):S5-S9.

9. Marteau P, Seksik P, Jian R. Probiotics and intestinal health effects: a clinical perspective. $\mathrm{Br} \mathrm{J}$ Nutr. 2002;88(suppl 1):S51-S57.

10. Isolauri $E$, Sutas $Y$, Kankaanpaa $P$, Arvilommi $H$, Salminen S. Probiotics: effects on immunity. Am J Clin Nutr. 2001;73(suppl 2):444S-450S.

11. Matsuzaki T. Immunomodulation by treatment with Lactobacillus casei strain Shirota. Int J Food Microbiol. 1998;41:133-140.

12. Cross ML, Stevenson LM, Gill HS. Anti-allergy properties of fermented foods: an important immunoregulatory mechanism of lactic acid bacteria? Int Immunopharmacol. 2001;1:891-901.

13. Hessle C, Hanson LA, Wold AE. Lactobacilli from human gastrointestinal mucosa are strong stimulators of IL-12 production. Clin Exp Immunol. 1999; 116:276-282.

14. Miettinen M, Matikainen S, Vuopio-Varkila J, et al. Lactobacilli and streptococci induce interleukin-12 (IL-12), IL-18, and gamma interferon production in human peripheral blood mononuclear cells. Infect Immun. 1998;66:6058-6062.

15. Murosaki S, Yamamoto $\mathrm{Y}$, Ito $\mathrm{K}$, et al. Heat-killed Lactobacillus plantarum $\mathrm{L}-137$ suppresses naturally fed antigen-specific IgE production by stimulation of IL-12 production in mice. J Allergy Clin Immunol. 1998;102:57-64.

16. Cross ML, Mortensen RR, Kudsk J, Gill HS. Dietary intake of Lactobacillus rhamnosus HNOO1 enhances production of both Th1 and Th2 cytokines in antigen-primed mice. Med Microbiol Immunol (Berl). 2002;191:49-53.

17. Pohjavuori E, Viljanen M, Korpela R, et al. Lactobacillus GG effect in increasing IFN-gamma production in infants with cow's milk allergy. J Allergy Clin Immunol. 2004;114:131-136.

18. Isolauri E, Arvola T, Sutas Y, Moilanen E, Salminen S. Probiotics in the management of atopic eczema. Clin Exp Allergy. 2000;30:1604-1610.

19. Kalliomaki M, Salminen S, Arvilommi H, Kero P, Koskinen $\mathrm{P}$, Isolauri E. Probiotics in primary prevention of atopic disease: a randomised placebo-controlled trial. Lancet. 2001;357:1076-1079.

20. Kalliomaki M, Salminen S, Poussa T, Arvilommi H, Isolauri E. Probiotics and prevention of atopic disease: 4-year follow-up of a randomised placebocontrolled trial. Lancet. 2003;361:1869-1871.

21. Rosenfeldt V, Benfeldt E, Nielsen SD, et al. Effect of probiotic Lactobacillus strains in children with atopic dermatitis. J Allergy Clin Immunol. 2003;111: 389-395.

22. Rosenfeldt $\mathrm{V}$, Benfeldt $\mathrm{E}$, Valerius $\mathrm{NH}$, Paerregaard A, Michaelsen KF. Effect of probiotics on gastrointestinal symptoms and small intestinal permeability in children with atopic dermatitis. J Pediatr. 2004; 145:612-616.

23. Majamaa $\mathrm{H}$, Isolauri E. Probiotics: a novel approach in the management of food allergy. J Allergy Clin Immunol. 1997;99:179-185.

24. Pessi T, Sutas Y, Hurme M, Isolauri E. Interleukin-10 generation in atopic children following oral Lacto- 
bacillus rhamnosus GG. Clin Exp Allergy. 2000;30: 1804-1808.

25. Wheeler JG, Bogle ML, Shema SJ, et al. Impact of dietary yogurt on immune function. Am J Med Sci. 1997;313:120-123.

26. Wheeler JG, Shema SJ, Bogle ML, et al. Immune and clinical impact of Lactobacillus acidophilus on asthma. Ann Allergy Asthma Immunol. 1997;79: 229-233.

27. Aldinucci C, Bellussi L, Monciatti G, et al. Effects of dietary yoghurt on immunological and clinical parameters of rhinopathic patients. Eur J Clin Nutr. 2002;56:1155-1161.

28. Helin T, Haahtela S, Haahtela T. No effect of oral treatment with an intestinal bacterial strain, Lactobacillus rhamnosus (ATCC 53103), on birch-pollen allergy: a placebo-controlled double-blind study. Allergy. 2002;57:243-246.

29. Sepp E, Julge K, Vasar M, Naaber P, Bjorksten B, Mikelsaar M. Intestinal microflora of Estonian and Swedish infants. Acta Paediatr. 1997;86:956-961.

30. Bjorksten B, Naaber P, Sepp E, Mikelsaar M. The intestinal microflora in allergic Estonian and Swedish 2-year-old children. Clin Exp Allergy. 1999;29: 342-346.

31. Kalliomaki M, Kirjavainen P, Eerola E, Kero P, Salminen S, Isolauri E. Distinct patterns of neonatal gut microflora in infants in whom atopy was and was not developing. J Allergy Clin Immunol. 2001;107: 129-134.

32. Saavedra JM, Abi-Hanna A, Moore N, Yolken RH. Long-term consumption of infant formulas containing live probiotic bacteria: tolerance and safety. Am J Clin Nutr. 2004;79:261-267.

33. US Food and Drug Administration. Agency Response Letter. GRAS Notice No. GRN 000049. Available online at: http://www.cfsan.fda.gov/ rdb/ opa-g049.html. Accessed December 7, 2005.

34. Wagner RD, Warner T, Roberts L, Farmer J, Balish E. Colonization of congenitally immunodeficient mice with probiotic bacteria. Infect Immun. 1997;65: 3345-3351.

35. Matricardi PM. Probiotics against allergy: data, doubts, and perspectives. Allergy. 2002;57:185187.

36. Matsuzaki T, Nagata Y, Kado S, Uchida K, Hashimoto S, Yokokura T. Effect of oral administration of Lactobacillus casei on alloxan-induced diabetes in mice. APMIS. 1997;105:637-642.

37. Matsuzaki T, Nagata Y, Kado S, et al. Prevention of onset in an insulin-dependent diabetes mellitus model, NOD mice, by oral feeding of Lactobacillus casei. APMIS. 1997;105:643-649.

38. Matsuzaki T, Yamazaki R, Hashimoto S, Yokokura T. The effect of oral feeding of Lactobacillus casei strain Shirota on immunoglobulin E production in mice. J Dairy Sci. 1998;81:48-53.

39. von der Weid T, Bulliard C, Schiffrin EJ. Induction by a lactic acid bacterium of a population of CD4(+) T cells with low proliferative capacity that produce transforming growth factor beta and interleukin-10. Clin Diagn Lab Immunol. 2001;8:695-701.

40. Sheil B, McCarthy J, O'Mahony L, et al. Is the mucosal route of administration essential for probiotic function? Subcutaneous administration is as- sociated with attenuation of murine colitis and arthritis. Gut. 2004;53:694-700.

41. Kato I, Endo-Tanaka K, Yokokura T. Suppressive effects of the oral administration of Lactobacillus casei on type II collagen-induced arthritis in DBA/1 mice. Life Sci. 1998;63:635-644.

42. Butler DM, Malfait AM, Maini RN, Brennan FM, Feldmann M. Anti-IL-12 and anti-TNF antibodies synergistically suppress the progression of murine collagen-induced arthritis. Eur J Immunol. 1999;29: 2205-2212.

43. Baharav E, Mor F, Halpern M, Weinberger A. Lactobacillus GG bacteria ameliorate arthritis in Lewis rats. J Nutr. 2004;134:1964-1969.

44. Toivanen P. From reactive arthritis to rheumatoid arthritis. J Autoimmun. 2001;16:369-371.

45. Hatakka K, Martio J, Korpela M, et al. Effects of probiotic therapy on the activity and activation of mild rheumatoid arthritis-a pilot study. Scand J Rheumatol. 2003;32:211-215.

46. Maassen CB, van Holten JC, Balk F, et al. Orally administered Lactobacillus strains differentially affect the direction and efficacy of the immune response. Vet Q. 1998;20(suppl 3):S81-S83.

47. Podolsky DK. Inflammatory bowel disease. N Engl J Med. 2002;347:417-429.

48. Fabia R, Ar'Rajab A, Johansson ML, et al. The effect of exogenous administration of Lactobacillus reuteri R2LC and oat fiber on acetic acid-induced colitis in the rat. Scand J Gastroenterol. 1993;28:155-162.

49. Osman N, Adawi D, Ahrne S, Jeppsson B, Molin G. Modulation of the effect of dextran sulfate sodiuminduced acute colitis by the administration of different probiotic strains of Lactobacillus and Bifidobacterium. Dig Dis Sci. 2004;49:320-327.

50. Kennedy RJ, Hoper M, Deodhar K, Kirk SJ, Gardiner $K R$. Probiotic therapy fails to improve gut permeability in a hapten model of colitis. Scand J Gastroenterol. 2000;35:1266-1271.

51. Kruis W, Fric P, Pokrotnieks $\mathrm{J}$, et al. Maintaining remission of ulcerative colitis with the probiotic Escherichia coli Nissle 1917 is as effective as with standard mesalazine. Gut. 2004;53:1617-1623.

52. Rembacken BJ, Snelling AM, Hawkey PM, Chalmers DM, Axon AT. Non-pathogenic Escherichia coli versus mesalazine for the treatment of ulcerative colitis: a randomised trial. Lancet. 1999;354: 635-639.

53. Mimura T, Rizzello F, Helwig U, et al. Once daily high dose probiotic therapy (VSL\#3) for maintaining remission in recurrent or refractory pouchitis. Gut. 2004;53:108-114.

54. Prantera C, Scribano ML, Falasco G, Andreoli A, Luzi C. Ineffectiveness of probiotics in preventing recurrence after curative resection for Crohn's disease: a randomised controlled trial with LactobacilIus GG. Gut. 2002;51:405-409.

55. Anderson KV. Toll signaling pathways in the innate immune response. Curr Opin Immunol. 2000;12:1319.

56. Akira S, Takeda K, Kaisho T. Toll-like receptors: critical proteins linking innate and acquired immunity. Nat Immunol. 2001;2:675-680.

57. Sturm A, Rilling K, Baumgart DC, et al. Escherichia coli Nissle 1917 distinctively modulates T-cell cy- 
cling and expansion via toll-like receptor 2 signaling. Infect Immun. 2005;73:1452-1465.

58. Rachmilewitz D, Katakura K, Karmeli F, et al. Tolllike receptor 9 signaling mediates the anti-inflammatory effects of probiotics in murine experimental colitis. Gastroenterology. 2004;126:520-528.

59. Di Giacinto C, Marinaro M, Sanchez M, Strober W, Boirivant M. Probiotics ameliorate recurrent Th1mediated murine colitis by inducing IL-10 and IL10 -dependent TGF- $\beta$-bearing regulatory cells. $\mathrm{J} \mathrm{Im-}$ munol. 2005;174:3237-3246.

60. Kapsenberg ML. Dendritic-cell control of pathogendriven T-cell polarization. Nat Rev Immunol. 2003; 3:984-993.

61. Christensen HR, Frokiaer H, Pestka JJ. Lactobacilli differentially modulate expression of cytokines and maturation surface markers in murine dendritic cells. J Immunol. 2002;168:171-178.

62. Mohamadzadeh M, Olson S, Kalina WV, et al. Lactobacilli activate human dendritic cells that skew $\mathrm{T}$ cells toward T helper 1 polarization. Proc Natl Acad Sci U S A. 2005;102:2880-2885.

63. Hart AL, Lammers K, Brigidi $P$, et al. Modulation of human dendritic cell phenotype and function by probiotic bacteria. Gut. 2004;53:1602-1609.

64. Braat H, van den Brande J, van Tol E, Hommes D, Peppelenbosch M, van Deventer S. Lactobacillus rhamnosus induces peripheral hyporesponsiveness in stimulated CD4+ T cells via modulation of dendritic cell function. Am J Clin Nutr. 2004;80:16181625.

65. Pelto L, Isolauri E, Lilius EM, Nuutila J, Salminen S. Probiotic bacteria down-regulate the milk-induced inflammatory response in milk-hypersensitive sub- jects but have an immunostimulatory effect in healthy subjects. Clin Exp Allergy. 1998;28:14741479.

66. Feord J. Lactic acid bacteria in a changing legislative environment. Antonie Van Leeuwenhoek. 2002; 82:353-360.

67. von Wright $A$. Regulating safety of probiotics-the European approach. Curr Pharm Des. 2005;11:1723.

68. Food and Agriculture Organization of the United Nations/World Health Organization. Guidelines for the Evaluation of Probiotics in Food: Report of a Joint FAO/WHO Working Group on Drafting Guidelines for the Evaluation of Probiotics in Food. Available at: ftp://ftp.fao.org/es/esn/food/wgreport2.pdf. Accessed December 7, 2005.

69. Salminen S, von Wright A, Morelli L, et al. Demonstration of safety of probiotics-a review. Int J Food Microbiol. 1998;44:93-106.

70. He F, Morita H, Ouwehand AC, et al. Stimulation of the secretion of pro-inflammatory cytokines by $\mathrm{Bi}-$ fidobacterium strains. Microbiol Immunol. 2002;46: 781-785.

71. European Commission Scientific Committee on Food. Report of the Scientific Committee on Food on the Revision of Essential Requirements of Infant Formulae and Follow-on Formulae. Available online at: http://europa.eu.int/comm/food/fs/sc/scf/out199_ en.pdf. Accessed December 7, 2005.

72. Agostoni C, Axelsson I, Braegger C, et al. Probiotic bacteria in dietetic products for infants: a commentary by the ESPGHAN Committee on Nutrition. $\mathrm{J} \mathrm{Pe}$ diatr Gastroenterol Nutr. 2004;38:365-374. 